\title{
Calidad de las aguas residuales de tipo especial en la ciudad La Libertad, El Salvador
}

\section{Quality of special wastewater La Libertad, El Salvador}

\author{
Francisco Rosales-Ayala1, Dolores Rovira-Quezada², \\ Rooel Campos-Rodríguez ${ }^{3}$
}

Fecha de recepción: 16 de setiembre de 2018 Fecha de aceptación: 3 de diciembre de 2018

Rosales-Ayala, F; Rovira-Quezada, D; Campos-Rodríguez,

R. Calidad de las aguas residuales de tipo especial en la ciudad La Libertad, El Salvador. Tecnología en Marcha. Vol. 32-3. Julio-Setiembre 2019. Pág. 135-145.

DOI: https://doi.org/10.18845/tm.v32i3.4504

1 Investigador. Universidad Estatal a Distancia. Costa Rica. Correo electrónico: francisco.rosales@attecs.com.

2 Doctora en Ingeniería Química, profesora -investigadora del Departamento de Ingeniería de Procesos y Ciencias Ambientales, Universidad Centroamericana José Simeón Cañas, El Salvador. Correo electrónico: mrovira@uca.edu.sv. (iD) https://orcid.org/0000-0002-4869-2566

3 Doctor en Ciencias Naturales para el Desarrollo, profesor-investigador de la Escuela de Agronegocios. Coordinador del Área Académica Agroforestal Tecnológico de Costa Rica. Costa Rica. Correo electrónico: rocampos@tec.ac.cr. 


\title{
Palabras clave
}

Planta de Tratamiento de aguas residuales; muestra compuesta; influente; efluente.

\section{Resumen}

Esta investigación se realizó con el objetivo de caracterizar las aguas residuales de tipo especial que corresponden a las generadas por actividades agroindustriales e industriales. Específicamente se caracterizaron las aguas del mercado municipal y restaurantes, así como el influente y efluente de la planta de tratamiento donde llegan las mismas y el cuerpo receptor donde finalmente desembocan (Río Chilama) todo por medio de muestreos compuestos. Todas las aguas caracterizadas no cumplen con los estándares mínimos establecidos en normas salvadoreñas como la de Administración Nacional de Acueductos y Alcantarillados (ANDA) u otras normativas utilizadas en esta investigación, por lo que se limitan las posibilidades de un desarrollo sostenible, ya que empobrecen la estética, crean insalubridad y afectan los servicios ambientales potenciales de los cuerpos de agua superficial. Dado el crecimiento en la demanda turística que se está dando en la ciudad de La Libertad es necesaria el fortalecimiento en la gestión ambiental municipal con estrategias que posibiliten la mejora en el equipamiento urbano sanitario, y la aplicación de normativas ambientales respecto a las aguas residuales de tipo especial.

\section{Keywords}

Wastewater treatment plant; composite sample; influent; effluent.

\begin{abstract}
This research was carried out with the objective of characterizing the special type wastewater corresponding to those generated by agroindustrial and industrial activities. Specifically, the waters of the municipal market and restaurants were characterized, as well as the influent and effluent of the treatment plant where they arrive and the receiving body where they finally flow (Río Chilama) all through compound sampling.

All the waters characterized do not meet the minimum standards established in the standards or El Salvador (ANDA) or other regulations used in this investigation, which limits the possibilities of sustainable development, since they impoverish the aesthetics, create unhealthiness and affect the potential environmental services of surface water bodies.

Given the growth in tourist demand that is taking place in the city of La Libertad, it is necessary to strengthen municipal environmental management with strategies that enable improvement in urban health equipment, and the application of environmental regulations regarding wastewater from special type.
\end{abstract}

\section{Introducción}

La ciudad de la Libertad es una localidad costera que se ubica en la zona central de El Salvador. Está delimitada por dos ríos importantes, el Chilama al occidente y el río El Jute al oriente.

El sector económico de la ciudad está especialmente constituido alrededor de las actividades turísticas y comerciales, ya que el municipio de La Libertad es uno de los atractivos turísticos más emblemáticos del país, y a la vez representa un centro comercial importante para la comercialización de productos provenientes de siete municipios que lo rodean [1]. 
Las pequeñas ciudades ubicadas en zonas costeras tienen un alto potencial turístico y generalmente se explotan con este fin. Este desarrollo conlleva consigo presiones considerables sobre los recursos naturales existentes, especialmente los cuerpos de agua superficiales y subterráneos, debido a la demanda de lugareños, visitantes, turistas nacionales y extranjeros [2] y [3].

Las aguas residuales en centros poblacionales pueden ser tratadas en sistemas centralizados, los cuales constituyen sistemas de depuración que atienden toda una ciudad o descentralizada que atiende porciones de esta [4].

No obstante, en los países en vías de desarrollo los sistemas centralizados de manejo de aguas residuales presentan dificultades para su gestión, debido a que las inversiones para acceder a un sistema de tratamiento de este tipo resultan altas en términos de infraestructura, operación y mantenimiento [5].

Diversos autores sostienen que, en pequeños centros poblacionales o conglomerados de negocios, se pueden implementar sistemas de tratamiento descentralizados, los cuales requieren menor inversión, y menor gasto para la operación y mantenimiento. Estos sistemas presentan mayores posibilidades para la reutilización del agua tratada, y su gestión financiera puede llegar a ser más sencilla y sostenible en el tiempo, presentándose por esas razones como una buena alternativa para los países en vías de desarrollo [6], [7], [8], [9].

La libertad cuenta con una planta municipal aerobia de lodos activados, donde trata un caudal diario de $1123 \mathrm{~m}^{3}$ aproximadamente. Su construcción data de 1981, superando su vida útil. La planta no cuenta con la capacidad necesaria de depuración, puesto que solo alcanza el 50\% de remoción de carga orgánica [1].

En El Salvador la contaminación de cuerpos de agua superficiales se ha convertido en uno de los problemas ambientales más apremiantes, situación que provoca una disminución importante en la disponibilidad de los recursos hídricos, siendo el tipo de contaminación más generalizada la bacteriológica y orgánica, la cual incide gravemente sobre los ecosistemas acuáticos y terrestres [10]

Por tal motivo, la administración municipal de la ciudad La libertad consiente del problema, se propone caracterizar las aguas residuales de tipo especial, mismas que de acuerdo con la Norma Salvadoreña Obligatoria NSO 13.49.01:09, se define como la generada por actividades agroindustriales, industriales, hospitalarias y todas aquellas que no se consideran de tipo ordinario, es decir que sean generadas por actividades domésticas de los seres humanos, tales como uso de servicios sanitario, fregaderos, lavado de ropa y otras similares.

Para realizar la caracterización de aguas residuales de tipo especial se puede hacer por medio de un muestreo compuesto. Según [11] un muestreo compuesto se refiere a una serie de muestras que se recolectan a lo largo del tiempo (muestreo por tiempo), y que por tanto representan las características promedio de las aguas residuales. La muestra compuesta puede ser tomada con equipo automatizado. Para [11] el tiempo de muestreo compuesto depende de la concentración de contaminantes, la disponibilidad de equipos, el tipo de agua residual, la ubicación de los sitios de muestreo, entre otros. Por esto el investigador debe analizar cada uno de los criterios y proponer el programa de muestreo.

Respecto a los parámetros físico químicos a evaluar, [12] indica que es necesario analizar Demanda Química de Oxígeno (DQO) (mg/L), Demanda Biológica de Oxígeno (DBO5) (mg/l), Aceites y Grasas (mg/l), Sólidos Suspendidos Totales (SST) (mg/l), Sólidos Sedimentables (Ssed) (mg/l) y pH (unidades). 


\section{Metodología}

La ciudad de La Libertad es la cabecera del municipio del mismo nombre, que se localiza a su vez en el departamento de La Libertad, El Salvador. Se encuentra a una distancia en carretera de $30.4 \mathrm{~km}$ de la ciudad capital, por lo que la afluencia de turistas nacionales y extranjeros es importante, siendo esta de alrededor de un millón de turistas en el último año [13], lo que la coloca como uno de los polos turísticos más importantes en el país (figura 1).

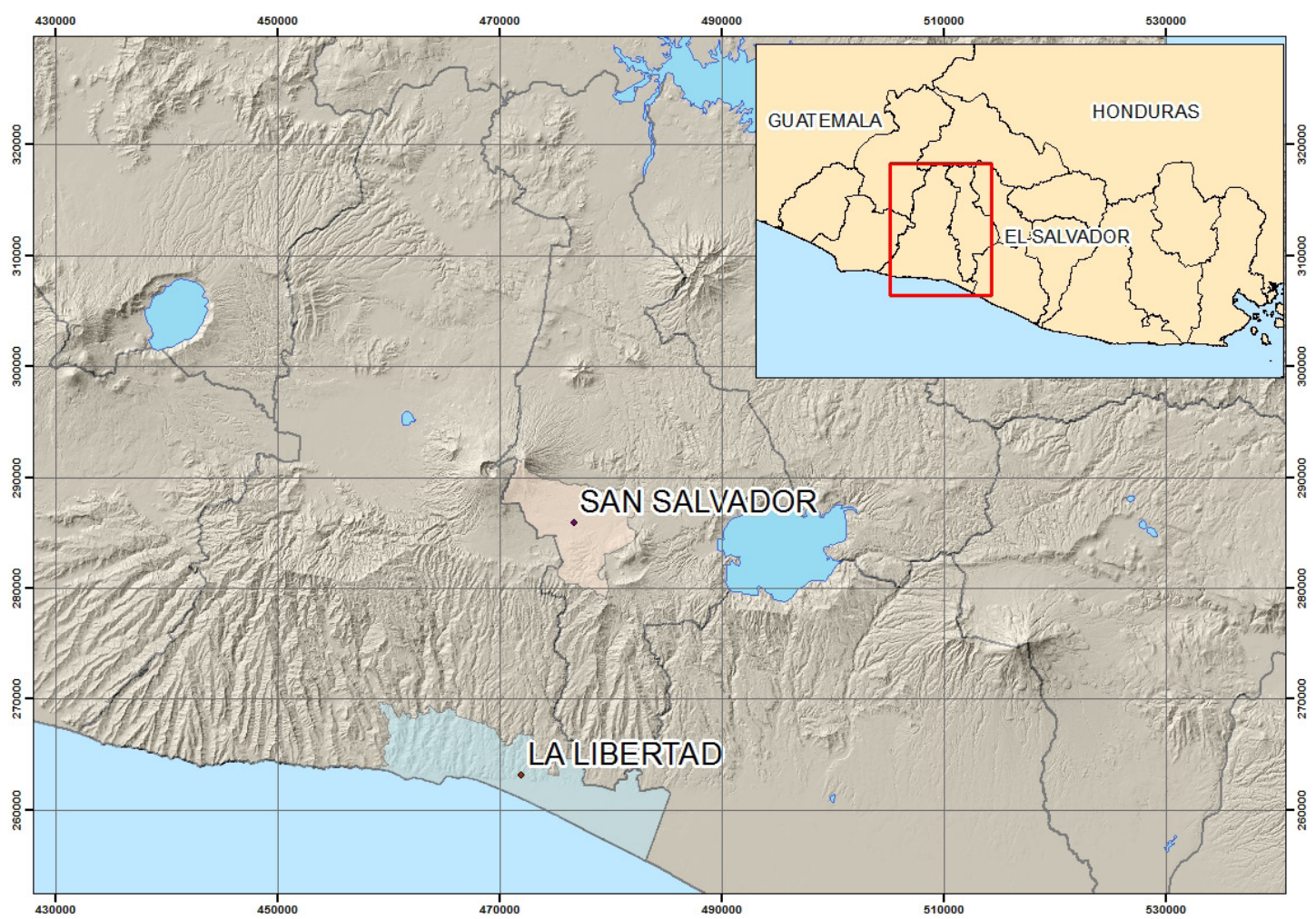

Figura 1. Ubicación de la ciudad de La Libertad en El Salvador

\section{Sitios de Muestreo}

Con el fin de caracterizar las aguas residuales de tipo especial, se realizaron muestreos en restaurantes, mercado municipal, en el influente y efluente de la planta de tratamiento municipal donde llegan las aguas de restaurantes y mercado municipal y el cuerpo receptor llamado Río Chilama.

\section{Selección de la muestra}

Según [1] la tipología de negocios e la ciudad La Libertad está conformado por 247 restaurantes que generan agua residual de tipo especial, ubicados en la fila costera de la ciudad y 51 locales en su gran mayoría representados por venta de alimentos, todos estos establecidos en un mercado municipal. 
Por el sistema de alcantarillado sanitario que posee La Libertad, las descargas de las aguas residuales del mercado municipal se concentran en dos puntos, mismos donde se realizaron las tomas de muestras.

Para el caso de los 247 restaurantes se realizó un cálculo de muestra al 95\% de confianza, resultado en 159 locales cuyas aguas se muestrearon en siete puntos de descarga.

\section{Muestreo compuesto}

Tanto para los negocios del mercado municipal como los restaurantes se aplicó la técnica de muestreo compuesto, según los procedimientos de [11].

Las muestras compuestas fueron basadas en tiempos (muestras de tiempo), estas consistieron en la toma de alícuotas discretas de igual volumen colectadas en periodos de tiempo iguales dentro de un contenedor, proceso que se realizó con muestreadores automáticos.

El muestreo se efectuó durante el mes de marzo del año 2017 y marzo 2018, esto con el fin de establecer la tendencia de los datos y contar con información suficiente que le diera validez al estudio, siguiendo las recomendaciones de [11].

Los muestreos se realizaron de lunes a domingo como una medida para captar diferencias en las características físico-químicas de los efluentes [14]. Al final del día se mezclaban las muestras horarias en un solo depósito, se etiquetaba, se disponía en una hielera con suficiente hielo para bajar la temperatura a $4^{\circ} \mathrm{C}$, y se transportaba al laboratorio acompañada de una cadena de custodia para su posterior análisis. Los muestreos fueron realizados en horas diurnas de 8:am a 4:00 pm debido a que en ese periodo se concentran las actividades comerciales y turísticas en la ciudad. Los muestreos fueron realizados en épocas de actividad comercial y turística promedio, fuera de temporadas pico, como son: semana santa, semana de vacaciones agostinas, y de fin de año.

Los resultados se compararon con los límites máximos permitidos por la Norma Salvadoreña de aguas residuales descargadas a cuerpo receptor, de la Administración Nacional de Acueductos y Alcantarillados (ANDA).

Se aplicaron pruebas estadísticas con el programa Infostat 2018, con un nivel de confianza del 95\% para determinar diferencias significativas entre los parámetros de un año al otro.

\section{Análisis de Laboratorio}

Se utilizaron los mismos parámetros de DQO $(\mathrm{mg} / \mathrm{l})$, DBO5 $(\mathrm{mg} / \mathrm{l})$, Aceites y Grasas $(\mathrm{mg} / \mathrm{l})$, Sólidos Suspendidos Totales SST (mg/l), Sólidos Sedimentables Ssed (mg/l) y pH (unidades) así como la metodología de análisis en laboratorio para restaurantes, mercado municipal, influente y efluente de la planta de tratamiento, tal y como lo indica [12] y [15]. Los análisis fueron realizados en un laboratorio acreditado bajo la norma ISO 17025.

\section{Influente y efluente de la planta de tratamiento municipal}

Se realizaron muestreos compuestos de ocho horas en el alcantarillado sanitario que alimentan la planta, como en su descarga en el río Chilama, esto durante un día en marzo 2017 y otro en marzo 2018, para determinar el nivel de eficiencia en la remoción de carga orgánica de la estación depuradora. Los resultados se contrastaron con la norma nacional que rige las descargas a cuerpo receptor [15]. 


\section{Caracterización del cuerpo de agua superficial}

La caracterización del río Chilama (cuerpo de agua superficial) se realizó mediante análisis físico-químico y microbiológico practicados a muestras puntuales obtenidas 50 metros aguas arriba y 50 metros aguas abajo de la planta de tratamiento ubicada en ese río.

Estos muestreos fueron realizados en junio 2018. Los parámetros estudiados para caracterizar las aguas fueron según [16] y la metodología utilizada para el muestreo fue de acuerdo a los procedimientos indicados por la Environmental Protection Agency (EPA) [11].

\section{Resultados y Discusión}

El cuadro 1 muestra los resultados de los parámetros físico químicos promedio de los restaurantes para marzo del año 2017 y 2018, donde se evidencia el incumplimiento con la norma ANDA, misma que regula las descargas de aguas residuales con el propósito de proteger los sistemas de alcantarillado sanitario y evitar las interferencias con tratamientos biológicos posteriores.

Cuadro 1. Análisis Físico Químicos de aguas residuales para restaurantes, marzo 2017 y 2018.

\begin{tabular}{|c|c|c|c|c|c|c|c|c|c|}
\hline & \multicolumn{5}{|c|}{ Marzo 2017} & \multicolumn{5}{c|}{ Marzo 2018 } & Mesviación \\
\hline Parámetro & Promedio & Máximo & Mínimo & $\begin{array}{c}\text { Desvínedio } \\
\text { estándar }\end{array}$ & Promáximo & Mínimo & $\begin{array}{c}\text { Desviación } \\
\text { estándar }\end{array}$ & $\begin{array}{c}\text { Norma } \\
\text { ANDA }\end{array}$ \\
\hline DQO (mg/L) & 2299,00 & 3438,00 & 1771,00 & 409,99 & 2356,14 & 3094,00 & 1829,00 & 355,07 & 1000,00 \\
\hline DBO $_{5}(\mathrm{mg} / \mathrm{L})$ & 1393,84 & 1920,00 & 1017,00 & 232,76 & 1370,48 & 1794,00 & 985,00 & 208,43 & 400,00 \\
\hline $\begin{array}{c}\text { Aceites y } \\
\text { grasas }(\mathrm{mg} / \mathrm{L})\end{array}$ & 165,69 & 261,00 & 12,00 & 53,40 & 166,93 & 285,00 & 26,00 & 66,70 & 150,00 \\
\hline SST $(\mathrm{mg} / \mathrm{L})$ & 712,55 & 1055,00 & 448,00 & 163,18 & 764,81 & 890,00 & 650,00 & 68,84 & 450,00 \\
\hline Ssed $(\mathrm{ml} / \mathrm{L})$ & 12,53 & 25,00 & 5,50 & 5,07 & 12,01 & 24,00 & 5,00 & 4,20 & 20,00 \\
\hline $\mathrm{pH}$ & 6,31 & 7,20 & 5,00 & 0,61 & 6,58 & 8,50 & 5,50 & 0,88 & $5,5-9,0$ \\
\hline
\end{tabular}

Los únicos dos valores promedio que cumplen con la norma ANDA son Ssed y pH, no obstante, los valores máximos de Ssed y mínimos de $\mathrm{pH}$ se encuentran fuera del rango permitido. Los valores de $\mathrm{pH}$ no presentan valores extremos (desviación estándar) debido a que en la limpieza de los restaurantes no se utilizan por lo general sustancias químicas que puedan alterarlo significativamente.

Realizando una comparación para ambos años respecto a los niveles promedio de DQO (2 299,0 - 2 356,14 mg/l), y de $\mathrm{DBO}_{5}$ (1 393,84 mg/l - 1370,48 mg/l) los mismos superan los valores permitidos en 2,3 veces la DQO y 3,4 la DBO5, lo que conlleva a una relación de $\mathrm{DBO}_{5} /$ DQO de 0,60 indicando el alto grado de contenido orgánico biodegradable, puesto que según [17] una relación 0,50 o mayor revela que las aguas poseen un bajo contenido de material orgánico refractario, lo que posibilitaría disminuir el impacto negativo en cuerpos de agua receptores y además posibilidades de reúso en riego e inodoros.

Los niveles de grasas y aceites promedio (165,69 - 166,93 mg/l), y SST (712,55 mg/l - 764,61 $\mathrm{mg} / \mathrm{l})$ provoca taponamientos frecuentes en las tuberías del alcantarillado sanitario dentro de la ciudad, afectando la estética, salubridad, y un aumento en los costos por mantenimientos correctivos para la Administración Municipal.

Un tratamiento en los puntos de origen de aguas (restaurantes), a través de la mejora de los hábitos culturales en las labores de limpieza de utensilios y alimentos, coadyuvaría con el 
adecuado manejo de las trampas de grasa y la disminución en la contaminación de las aguas residuales con lo que se reducirían costos operativos y de mantenimiento

La prueba estadística demuestra que no existen diferencias significativas entre los parámetros evaluados para restaurantes entre año 2017 y 2018 ( $p$ > 0,05), lo que sugiere que la calidad del agua residual es similar y los hábitos sobre la gestión de las aguas se mantienen.

El cuadro 2 presenta los valores de parámetros físico-químicos obtenidos de las pruebas de laboratorio para el mercado municipal, donde se aprecia que no cumplieran con la normativa de ANDA.

Cuadro 2. Análisis Físico Químicos de aguas residuales para mercado municipal, marzo 2017 y 2018.

\begin{tabular}{|c|c|c|c|c|c|c|c|c|c|}
\hline & \multicolumn{4}{|c|}{ Marzo 2017} & \multicolumn{4}{|c|}{ Marzo 2018} & \\
\hline Parámetro & Promedio & Máximo & Mínimo & $\begin{array}{l}\text { Desviación } \\
\text { estándar }\end{array}$ & Promedio & Máximo & Mínimo & $\begin{array}{l}\text { Desviación } \\
\text { estándar }\end{array}$ & $\begin{array}{l}\text { Norma } \\
\text { ANDA }\end{array}$ \\
\hline $\mathrm{DQO}(\mathrm{mg} / \mathrm{L})$ & 2676,9 & 3438,0 & 2074,0 & 492,4 & 2564,0 & 3256,0 & 1829,0 & 532,6 & 1000,0 \\
\hline $\mathrm{DBO}_{5}(\mathrm{mg} / \mathrm{L})$ & 1646,7 & 2160,0 & 1151,0 & 343,1 & 1562,7 & 2120,0 & 1115,0 & 339,9 & 400,0 \\
\hline $\begin{array}{c}\text { Aceites y grasas } \\
(\mathrm{mg} / \mathrm{L})\end{array}$ & 233,6 & 331,0 & 180,0 & 51,8 & 247,7 & 340,0 & 126,0 & 77,2 & 150,0 \\
\hline SST (mg/L) & 924,1 & 1340,0 & 560,0 & 247,3 & 961,9 & 1250,0 & 330,0 & 298,9 & 450,0 \\
\hline Ssed (ml/L) & 32,1 & 62,0 & 10,0 & 17,6 & 37,1 & 100,0 & 20,0 & 28,0 & 20,0 \\
\hline $\mathrm{pH}$ & 7,0 & 8,1 & 6,4 & 0,5 & 6,9 & 8,4 & 5,8 & 0,8 & $5,5-9,0$ \\
\hline
\end{tabular}

Los niveles promedio de $\mathrm{DBO}_{5}$ y DQO sobrepasan en 2,6 veces la $\mathrm{DQO}$ y 4,0 veces la $\mathrm{DBO}_{5}$., siendo la relación de estos dos parámetros de 0,61, por lo que las aguas son de alto contenido orgánico biodegradable.

Los altos niveles promedio de grasas, aceites y SST indican que los niveles de $\mathrm{DBO}_{5}$ y DQO se incrementan por contenido orgánico no disuelto en el agua, y sugiere mejorar las prácticas culturales de limpieza en los puntos de generación.

No se encontraron diferencias significativas $(p>0,05)$ para los parámetros de un año a otro, infiriendo que la calidad del agua se mantiene por debajo de los máximos permitidos por la norma.

El cuadro 3 muestra los resultados de los análisis físico-químicos de las muestras tomadas en el alcantarillado que alimenta la planta de tratamiento y la descarga de esta al río Chilama.

La planta de Tratamiento de la municipalidad de La Libertad es de tipo aerobia de lodos activados. Esto significa que es un bioproceso que pretende la depuración natural de las aguas residuales, realizando un tratamiento aerobio de las mismas, en el cual un cultivo de microorganismos oxida la materia orgánica, y un conjunto de procesos de biodegradación y biosíntesis cuya finalidad es la generación de un agua sin materia orgánica en suspensión (clarificado), bajo en $\mathrm{DBO}_{5}$, SST y turbidez.

En la parte primaria del proceso se separan sólidos mediante un sistema de cribado con rejillas, un desarenador para la eliminación de arenas, y un interceptor de grasas y aceites.

Seguidamente el tratamiento biológico o secundario está compuesto por un reactor biológico de lodos activados de aireación prolongada, en donde colonias bacterianas en forma de flóculos, metabolizan la carga orgánica biodegradable contenida en el agua residual. El reactor 
es acompañado de un clarificador secundario, que separa el agua tratada de los fangos biológicos, los cuales son retornados al reactor para continuar con el proceso depurativo.

Finalmente, el agua clarificada es Ilevada a una cámara de cloración, en donde se les aplican compuestos sanitizantes, como hipoclorito de sodio, para eliminar la carga biológica que contiene, para posteriormente verterla a un cuerpo receptor de agua.

Cuadro 3. Influente y efluente de la planta de tratamiento municipal de La Libertad.

\begin{tabular}{|c|c|c|c|c|c|c|c|}
\hline \multirow[b]{2}{*}{ Parámetros } & \multicolumn{3}{|c|}{ Marzo de 2017} & \multicolumn{3}{|c|}{ Marzo de 2018} & \multirow{2}{*}{$\begin{array}{l}\text { NSO.13.49.01:09 } \\
\text { Valores máximos en } \\
\text { la descarga }\end{array}$} \\
\hline & Influente & Efluente & Eficiencia & Influente & Efluente & Eficiencia & \\
\hline $\mathrm{DQO}(\mathrm{mg} / \mathrm{l})$ & 550,0 & 310,0 & $44 \%$ & 562,0 & 237,0 & $58 \%$ & 150 \\
\hline $\mathrm{DBO}_{5}(\mathrm{mg} / \mathrm{l})$ & 262,0 & 126,0 & $52 \%$ & 302,0 & 112,0 & $63 \%$ & 60 \\
\hline $\begin{array}{l}\text { Aceites y Grasas } \\
\qquad(\mathrm{mg} / \mathrm{l})\end{array}$ & 59,5 & 27,5 & $54 \%$ & 72,7 & 21,5 & $70 \%$ & 20 \\
\hline SST (mg/l) & 255,0 & 200,0 & $22 \%$ & 320,0 & 81,0 & $75 \%$ & 20 \\
\hline Ssed (ml/l) & 3,5 & 1,5 & $57 \%$ & 5,4 & 0,2 & $96 \%$ & 1 \\
\hline $\mathrm{pH}$ (unidades) & 7,3 & 7,6 & & 7,6 & 7,1 & & $5,5-9,0$ \\
\hline
\end{tabular}

Se puede notar como la eficiencia de la planta de tratamiento en la remoción de $\mathrm{DBO}_{5}$ fue del 52\% en marzo del 2017 y del 63\% en el mismo mes del 2018, estas eficiencias son bajas tomando en cuenta que para el tipo de proceso lo esperado son valores cercanos al 95\% [18].

Otro parámetro relevante de revisar en este tipo de planta de tratamientos son las grasas y aceites debido a que las mismas obstaculizan la actividad metabólica de las bacterias, puesto que interfieren en la transferencia de oxígeno.

Según los resultados obtenidos en grasas y aceites, no se cumple con la norma, puesto se supera el límite en un 37,5\% (año 2017) y en 8,5\% (año 2018), y esto dificulta la transferencia de oxígeno y aumentan la turbidez afectando de esta manera la vida acuática y las posibilidades de uso y recreación.

El cuadro 4 presenta los datos del cuerpo receptor (Río Chilama), donde descarga la planta de tratamiento. Los valores guía fueron establecidos por el Ministerio del Ambiente y Recursos Naturales (MARN) de El Salvador, mismos que están respaldados por diferentes normas.

Cuadro 4. Parámetros físico químicos aguas arriba y abajo de la descarga de la planta de tratamiento municipal.

\begin{tabular}{|c|c|c|c|c|}
\hline Parámetro físico-químico & Aguas Arriba & Aguas Abajo & Valor guía & Norma \\
\hline DBO5 (mg/l) & 2,1 & 17,8 & $<4$ & $\begin{array}{c}\text { No. } \\
\text { 33903-MINAE-S } \\
\text { (Costa Rica) }\end{array}$ \\
\hline Turbidez (NTU) & 10,0 & 18,0 & $<50,0$ & US EPA \\
\hline Oxígeno Disuelto & 6,2 & 4,4 & $>5,0$ & $\begin{array}{c}\text { D.S. No 015- } \\
\text { 2015-NIMAM } \\
\text { (Perú) }\end{array}$ \\
\hline pH & 7,8 & 7,3 & 6,0 a 9,0 & $\begin{array}{c}\text { D.S. No 015- } \\
\text { 2015-NIMAM } \\
\text { (Perú) }\end{array}$ \\
\hline Coliformes Fecales (NMP/100ml) & 350,0 & 12800,0 & $<200,0$ & US EPA \\
\hline
\end{tabular}


Los resultados de Coliformes fecales, indican que el río Chilama presenta un impacto aguas arriba, que lo vuelve no apto para actividades recreativas sin restricción, debido a que supera en $150 \mathrm{NMP} / 100 \mathrm{ml}$ la norma.

La carga orgánica representada por la $\mathrm{DBO}_{5}$ se incrementa en un $747,6 \%$, al pasar de aguas arriba a aguas abajo (2,8 a 17,8 mg/l), lo que indica que la descarga de la planta afecta significativamente la calidad del agua del río. Lo anterior repercute en que el oxígeno disuelto decrezca por debajo de los $5 \mathrm{mg} / \mathrm{l}$, debido a la actividad metabólica de las bacterias, al consumir la materia orgánica.

Respecto a la turbidez, aguas arriba el río presenta un nivel de 10 NTU y aumenta en un 80\% luego de la descarga, significando que ésta contribuye con sólidos suspendidos, no obstante, se cumple con el valor guía. A pesar de que este valor guía cumple, en términos generales los demás resultados obtenidos infieren una alta contaminación del río Chilama.

\section{Conclusiones}

Es evidente la contaminación de las aguas residuales provenientes de los restaurantes y del mercado municipal, con valores en todos los parámetros que superan por mucho lo establecido en la norma, lo que sin duda debe ser una llamada de atención para las autoridades, por el potencial impacto negativo a la salud de los habitantes, los turistas, la fauna marina, los diferentes ecosistemas acuáticos y terrestres y en general al componente ambiental, repercutiendo todo esto en el sector económico de La Libertad.

Siendo que no se encontraron diferencias estadísticamente significativas entre los muestreos realizados en el año 2017 y 2018, para restaurantes y mercado municipal se puede concluir que la calidad del agua es deficiente en ambos casos y que el tipo de contaminantes son relativamente similares, no obstante, se vislumbra una gran ventana de oportunidades dado que las aguas son altamente biodegradables, por lo que tratamientos de tipo biológico coadyuvaría a la disminución de la carga contaminante.

La planta de tratamiento municipal de aguas residuales presenta un nivel de eficiencia bajo, que impide que esta pueda descargar a niveles que no impacten negativamente la calidad del río Chilama. Los valores de $\mathrm{DBO}_{5}$, grasas y aceites demuestran poca remoción de la carga contaminante (cercana al 50\%), lo que está provocando problemas en la transferencia de oxígeno y elevando la turbidez del agua.

El río Chilama se encuentra contaminado, puesto que desde la planta de tratamiento las aguas no alcanzan una remoción significativa de impurezas, dado que se adiciona carga orgánica y por tanto se incrementa el nivel de contaminación bacteriana, afectando la biodiversidad del río y básicamente excluyéndolo para que se desarrollen actividades recreativas o de otra índole por la potencial afectación al ser humano.

Es claro que la contaminación de las aguas, así como del río Chilama se puede deber en cierta medida a comportamientos de los pobladores de La Libertad, también a políticas públicas sostenibles y planes de acción respecto a la gestión de las aguas residuales. La mala gestión en los puntos de origen, la poca eficiencia de la planta de tratamiento municipal aunado a la baja o nula inversión en educación ambiental coadyuva a la contaminación de los cuerpos de agua superficiales, afecta la salubridad dentro la ciudad, y la estética de esta, disminuyendo las posibilidades de un desarrollo social y económico del municipio en armonía con el ambiente.

Por tal motivo, es importante determinar los niveles de conocimientos, las actitudes y las posibles barreras que los pobladores tengan respecto a este tema con el propósito de generar cambios que ayuden a superar los obstáculos para un mejor manejo de las aguas residuales de tipo especial. 


\section{Agradecimientos}

A la Alcaldía Municipal de La Libertad por el apoyo brindado a este estudio.

\section{Referencias}

[1] F. Rosales-Ayala y Campos-RodríguezR., "Gestión de las aguas residuales en la ciudad La Libertad, El Salvado»r, TM, vol. 32, n. ${ }^{\circ}$ 2, pp. Pág. 43-53, may 2019.

[2] R. Cullen y A. Dakers. Tourism, Water, Wastewater and Waste Services in Small Towns Tourism Recreation Research and Education Center. [En Línea] Disponible en https://www.researchgate.net/ profile/Ross Cullen/publication/27814695 Tourism water wastewater and waste services in small towns/ links/0deec5208f5fb626cc000000/Tourism-water-wastewater-and-waste-services-in-small-towns.pdf. [Accedido el 10 de febrero del 2018]

[3] A. Dakers, D. Lees, R. Cullen y G. Meyer. Impact of Tourism on Water and Wastewater Services in Small Towns. [En Línea] Disponible en http://www.ecoeng.co.nz/wp-content/uploads/2010/11/tourismimpacts.pdf. [Accedido el 23 de mayo 2018]

[4] R. Crities y G. Tchobanoglous, "Tratamiento de Aguas Residuales en Pequeñas Poblaciones", Bogotá, Colombia: McGraw-Hill, 2000.

[5] Z. Ujang y M. Henze, "Municipal Wastewater Management in Developing Countries : Principles and Engineering. IWA" [En Línea] Disponible en http://orbit.dtu.dk/en/publications/municipal-wastewater-management-in-developing-countries(ece7837c-c6f0-4851-b7aa-19eb8237be9e).html. [Accedido 03 de junio 2018].

[6] M. Massoud y J. Nasar, "Decentralized Approaches to Wastewater Treatment and Management: Applicability in Developing Countries" Journal of Environmental Management Vol.90, №1, pp. 652-59, 2009.

[7] J. Parkinson y K. Tayler, "Decentralized Wastewater Management in Peri-Urban Areas in Low-Income Countries. Environment and Urbanization", Vol 15, № 1, pp 75-90, 2003. DOI:10.1177/095624780301500119

[8] E. Medilanski, C. Liang, H. Mosler, R. Schertenleib y T. Larsen, "Wastewater Management in Kunming, China: A Stakeholder Perspective on Measures at the Source. Environment and Urbanization", Vol 18, №2, pp 353-378, 2006. DOI:10.1177/0956247806069615.

[9] D. Robbins, Guidance for Improving Sanitation in El Salvador's Tourism Areas Through Decentralized Wastewater Management Systems. Guidance for Improving Sanitation in El Salvador's Tourism Areas through Decentralized Wastewater Management Systems. RTI International [En Línea] Disponible en https://www.cabdirect.org/cabdirect/abstract/20133328368. [Accedido 16 de agosto, 2018]

[10] MARN. Ministerio de Medio Ambiente y Recuros Naturales, Informe de La Calidad Del Agua de Los Ríos de El Salvador 2017 [En Línea] Disponible en http://www.marn.gob.sv/descargas/Documentos/2018/Informe de la calidad de agua 2018.pdf [Accedido 24 de octubre, 2018]

[11] Environmental Protection Agency (EPA), Wastewater Sampling 2017. [En Línea] Disponible en https://www.epa. gov/sites/production/files/2015-06/documents/Wastewater-Sampling.pdf [Accedido 10 de setiembre 2018]

[12] Administración Nacional de Acueductos y Alcantarillados (ANDA), Normas para regular calidad de aguas residuales de tipo especial descargadas al alcantarillado sanitario. [En Línea] Disponible en http://www.anda.gob. sv/wp-content/uploads/2015/04/aguas-residuales.pdf [Accedido 02 de enero 2017]

[13] Presidencia República de El Salvador, Polo turístico de La Libertad: Gobierno trabajando en grande 2017. [En Línea] Disponible en http://www.presidencia.gob.sv/polo-turistico-de-la-libertad-gobierno-trabajando-engrande/ [Accedido 6 de mayo 2018]

[14] O. Garza, B. Lesikar, R. Persyn, A. Kenimer, M. Anderson. Food service wastewater characteristics as influenced by management practice and pirmary cuisine type, [En Línea] Disponible en https://agrilifecdn.tamu.edu/ossf/ files/2011/06/Food-Service-Wastewater-Paper.pdf. [Accedido el 20 de septiembre de 2018]

[15] Administración Nacional de Acueductos y Alcantarillados (ANDA), Norma Salvadoreña de aguas residuales descargadas a cuerpo receptor. [En Línea] Disponible en http://www.marn.gob.sv/descarga/norma-aguasresiduales-descargadas-a-cuerpo-receptor-nso-13-49-01-09/?wpdmdl=23913\&ind=xA3LQHZRC9puoO X5rID QQSbDU-oOQeps3ecf2rYWcwYg9aoFrSDmghVv7jcYDsHZHZcOfxNJ9IBPFCHdt4JyQFEWhGftOYvHyMAOgKKPRKYTB Z5HkpTyLem1Keg3cMF [Accedido 22 de junio 2017] 
[16] Reglamento Especial de Normas Técnicas de Calidad Ambiental. República de El Salvador. [En Línea] Disponible en http://www.marn.gob.sv/descarga/reglamento-especial-de-normas-tecnicas-de-calidadambiental/?wpdmdl=18044\&ind=33 aC7Ha6DpSJUMPXc9-cKOWvrkhS6p6IOgSMI7sFg7EK04ekQaBrMTa9LaUY1p2qCKWb49YJDZMWgC5jtIwARxN3PP-8kFXMtMca_TV8HQ [Accedido 4 de diciembre 2018]

[17] Metcalf y Eddy. Wastewater Engineering. Treatment and Resource Recovery.2014. 5ta edición. McGraw Hill.

[18] Metcalf y Eddy. Ingeniería de aguas residuales. Tratamiento, vertido y reutilización. 1996. 3ra edición. McGraw Hill. 